\title{
Simplifying of DLT Equations for a Single Digital Image and its Application in Architectural Façades Documentation
}

\author{
Mohamed A. M. Abbas, Ibrahim F. Shaker, Ahmed K. Abdel-Gawad, Alaa Al Din I. Awad
}

\begin{abstract}
Survey of architectural façades to obtain elevation drawings is an essential, especially in case of maintenance, restoration, ...etc. On the other hand, the rapid progress of the obtained image size captured by digital cameras opens new areas for the captured images to be used in photogrammetry. One of these new areas is the use of a single digital image for surveying and recording of architectural façades. So, the main objective of the current research is to develop a computer algorithm using least squares adjustment method for studying the practical visibility, applicability, and accuracy of using a single digital image captured by a digital camera in surveying architectural façades. To achieve the above-mentioned goal, simplified formulas obtained from collinearity condition, the basis of the Direct Linear Transformation model (DLT), to suit the architectural façades conditions, which is the façade lies in one vertical plane. The obtained formulas showed that eight transformation parameters are required (needed) between the architectural façade and the captured image. Hence, the eight parameters can be computed using four common points or more. So, two field experiments were made on two architectural façades to test the practical visibility, applicability, and accuracy of the supposed technique. The obtained results proved the success of the supposed technique and its related computer algorithm in the survey and the record of the vertical architectural façades.
\end{abstract}

Keywords: Computer Algorithm, Direct Linear Transformation, Façade Documentation, Photogrammetry, Single Digital Image, Surveying.

\section{INTRODUCTION}

Mentioned Architectural façades surveys are carried out for various reasons such as validation, maintenance or facility management, alterations and additions, restoration, and simply recording of the architecture and its details [1], [2], [3], [4], and [5]. The drawings are presented as elevations. So, if photogrammetry is used for façade recordings, elevation drawings can be produced with higher degree of detail and less effort. One of the photogrammetric techniques is the single image photogrammetry, which deals with the extraction of geometric information using only one photo.

Revised Manuscript Received on January 22, 2020.

* Correspondence Author

Mohamed A. M. Abbas*, Researcher, Public Works Department of Faculty of Engineering, Ain Shams University, Egypt.

Ibrahim F. Shaker, Professor, Department of Faculty of Engineering, Ain Shams University, Egypt.

Ahmed K. Abdel-Gawad, Professor, Department of Civil Engineering, National Research Centre, Egypt.

Alaa Al Din I. Awad, Assistant Professor of Ssurveying, Public Works Department, Faculty of Engineering, Ain Shams University, Egypt.

(c) The Authors. Published by Blue Eyes Intelligence Engineering and Sciences Publication (BEIESP). This is an open access article under the CC BY-NC-ND license (http://creativecommons.org/licenses/by-nc-nd/4.0/)
So, the Direct Linear Transformation technique (DLT) can be used to transform the façade points from the image coordinates system to the façade coordinates system. On the other hand, more and more digital cameras are available in the market with reasonable price. Also, it is well known that documentation and producing of elevation drawings of architectural façades can be done using traditional surveying techniques as well as photogrammetric techniques. The advantage of those image maps compared to line drawings is the higher degree of details with less effort [6] and [7].

The traditional surveying techniques include mainly the intersection method and direct observation using total station and non prism technique. On the other hand, the photogrammetric techniques, include many techniques, one of them, is by using one digital image only for measuring the features of architectural façades. So, the present study will be concentrated on this technique.

The advantages of using the photogrammetric concept in surveying architectural façades instead of traditional surveying techniques are:

- Fieldwork is minimum and faster.

- Repetition of measurements is easier.

- A permanent record is taken of very large number of target points.

- There is no physical contact with the objects, i.e. no necessity to occupy the targets.

- Photo coordinates measurements with a high degree of accuracy can be obtained, due to the large scale of the taken photographs.

- There is more flexibility in the choice of points to be measured on the recorded image.

- Different models present no additional problems in the photogrammetric method.

According to the above discussion, it can be seen that the photogrammetric method provides information at very large number of points at the same epoch. Also, the processing of digital images is faster and easier than processing of printed photos [8]. Consequently, the main objective of this paper is to asses the developed computer algorithm obtained for transforming a digital image captured by a digital camera for documentation, surveying and producing elevation drawings of architectural façades. In other words, the main interest here is oriented towards the practical visibility, as well as the achieved accuracy of this technique, on the basis of actual field experimental data. If this objective is verified, the proposed technique could manifest itself to replace the teddies traditional surveying techniques for detailed surveying of architectural façades. 


\section{Simplifying of DLT Equations for a Single Digital Image and its Application in Architectural Façades Documentation}

Hence, the present paper investigates the rigorous solution comes from the Direct Linear Transformation (DLT) of a single image in a fully automated fashion. Of course, this will necessitate the development of a new appropriate computer program, based on rigorous algorithm, using the parametric least squares adjustment method. In this context, and in order to achieve our objective here, the methodology of direct linear transformation procedure will be discussed first. Then, the developed program will be briefly represented with its essential characteristics only. After that, the used actual data in our application here will be described. Discussion of obtained results for testing the reliability and resolution of the developed program, for automatic transformation for map production from a single digital image will be outlined.

\section{THE FUNDAMENTAL CONCEPT OF THE DEVELOPED MATHEMATICAL MODEL PROCEDURE}

\section{A.DIRECT LINEAR TRANSFORMATION DEVELOPED SIMPLIFIED MODEL}

Two reference frames are defined in Fig. 1; object-space reference frame (XYZ system) and image-plane reference frame (xy-system). The optical system of the camera/projector maps point $\mathrm{O}$ in the object space to image $\mathrm{o}$ in the image plane. [X, Y, Z] are the object-space coordinates of point $\mathrm{O}$ while $[\mathrm{x}, \mathrm{y}$ ] are the image-plane coordinates of the image point $\mathrm{o}$. Points $\mathrm{o}, \mathrm{N}$ and $\mathrm{O}$ are thus collinear. This is the so-called collinearity condition, the basis of the Direct Linear Transformation method (DLT). The DLT model is as follow [9] and [10]:

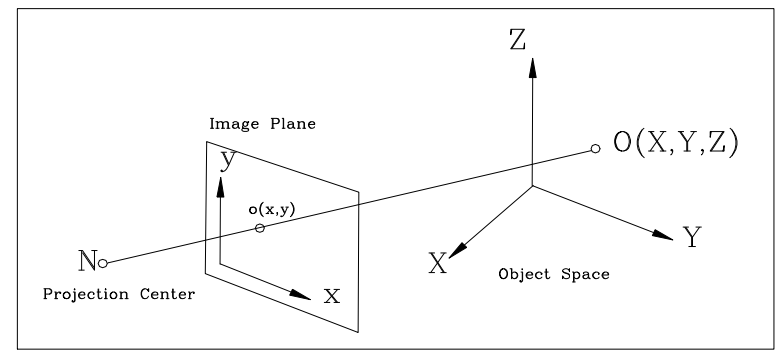

Fig. 1: Object-space reference frame (the XYZ-system) and image-plane reference frame (the xy-system).

$x=\frac{L_{1} X+L_{2} Y+L_{3} Z+L_{4}}{L_{9} X+L_{10} Y+L_{11} Z+1}$

$y=\frac{L_{5} X+L_{6} Y+L_{7} Z+L_{8}}{L_{9} X+L_{10} Y+L_{11} Z+1}$

Where:

$\mathrm{x}, \mathrm{y}$ : The image coordinates of a point.

X, Y, Z: The object-space coordinates of a point.

L1 to L11: The Direct Linear Transformation parameters.

In the current investigation, if another space coordinate system is defined that, its $X^{\prime}$-axis and $Z^{\prime}$ axis are located at the façade vertical plane, and its $Y^{\prime}$ axis is perpendicular to the plane, so, the value of $Y^{\prime}$ coordinate for all points in the $X^{\prime} Z^{\prime}$ plane will be equal to zero. In this context, by substituting $\mathrm{Y}^{\prime}$ value by zero in equations (1) and (2), equations (3) and (4) are obtained:

$x=\frac{L_{1} X^{\backslash}+L_{3} Z^{\backslash}+L_{4}}{L_{9} X^{\backslash}+L_{11} Z^{\backslash}+1}$
$y=\frac{L_{5} X^{\backslash}+L_{7} Z^{\backslash}+L_{8}}{L_{9} X^{\backslash}+L_{11} Z^{\backslash}+1}$

Where:

$\mathrm{X}^{\backslash}$ and $\mathrm{Z}$ : The coordinates of a point in the façade coordinates system.

For more simplifying of equations (3) and (4), especially for the purpose of computer programming, equations (5), (6) and (7) are established from equations (3) and (4).

$\left(\begin{array}{cccccccc}X^{\backslash} & Z^{\backslash} & 1 & 0 & 0 & 0 & -x X^{\backslash} & -x Z^{\backslash} \\ 0 & 0 & 0 & X^{\backslash} & Z^{\backslash} & 1 & -y X^{\backslash} & -y Z^{\backslash}\end{array}\right)\left(\begin{array}{l}L_{1} \\ L_{3} \\ L_{4} \\ L_{5} \\ L_{7} \\ L_{8} \\ L_{9} \\ L_{11}\end{array}\right)=\left(\begin{array}{l}x \\ y\end{array}\right)$

$X^{\prime}=\frac{a_{2} * a_{6}-a_{3} * a_{5}}{a_{2} * a_{4}-a_{1} * a_{5}}$

$Z^{\prime}=\frac{a_{1} * a_{6}-a_{3} * a_{4}}{a_{2} * a_{4}-a_{1} * a_{5}}$

Where:

$a_{1}=L_{1}-x L_{9}$

$a_{2}=L_{3}-x L_{11}$

$a_{3}=L_{4}-x$

$a_{4}=L_{5}-y L_{9}$

$a_{5}=L_{7}-y L_{11}$

$a_{6}=L_{8}-y$

\section{B.LEAST SQUARES AdJUSTMENT METHOD}

Least squares adjustment is a model for the solution of an over determined system of equations based on the principle of least squares of observation residuals. It is used extensively in the disciplines of surveying. There are three forms of least squares adjustment: parametric, conditional, and combined. In the parametric adjustment, one can find an observation equation $F(X)=w$ relating observations $w$ explicitly in terms of parameters $\mathrm{X}$, leading to the model below [11]:

$F(X)=w$

One can proceed to Taylor series expansion of the equations, which results in the Jacobians or design matrices,(A):

$A=\frac{\partial F}{\partial X}$

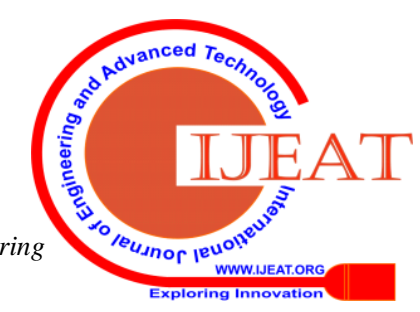


So, the solution will be:

$X=\left(A^{T} P A\right)^{-1}\left(A^{T} P w\right)$

Where:

$\mathrm{X}$ : The Solution vector.

P: The Weight matrix

\section{DEVELOPED COMPUTER ROUTINE NEEDED FOR THE SOLUTION OF DIRECT LINEAR TRANSFORMATION PROBLEMS}

The main characteristics of the required program to be developed, which is called here as TRANSFORM, including its input data, program algorithm steps and flow-charts, as well as the output results. Such program is written in Visual Basic computer language, which is working efficiently on IBM compatible PC computers, with modest capacity.
The required input data is the following files:

- The image file (*.txt) which contains the image coordinates measured at the image coordinates system from the image.

- The map file (*.txt) which contains the ground coordinates measured at the site using the total station at the façade coordinates system (e.g. $X^{\prime}$ and $Z^{\prime}$ ).

- Number of common points between the two mentioned coordinates systems needed to calculate the eight transformation parameters.

\section{B.Program Algorithm Steps AND Flow-CHART:}

The basic flow-chart of program TRANSFORM is depicted in Fig. 2, while the main program steps will be summarized below:

\section{A.INPUT DATA:}

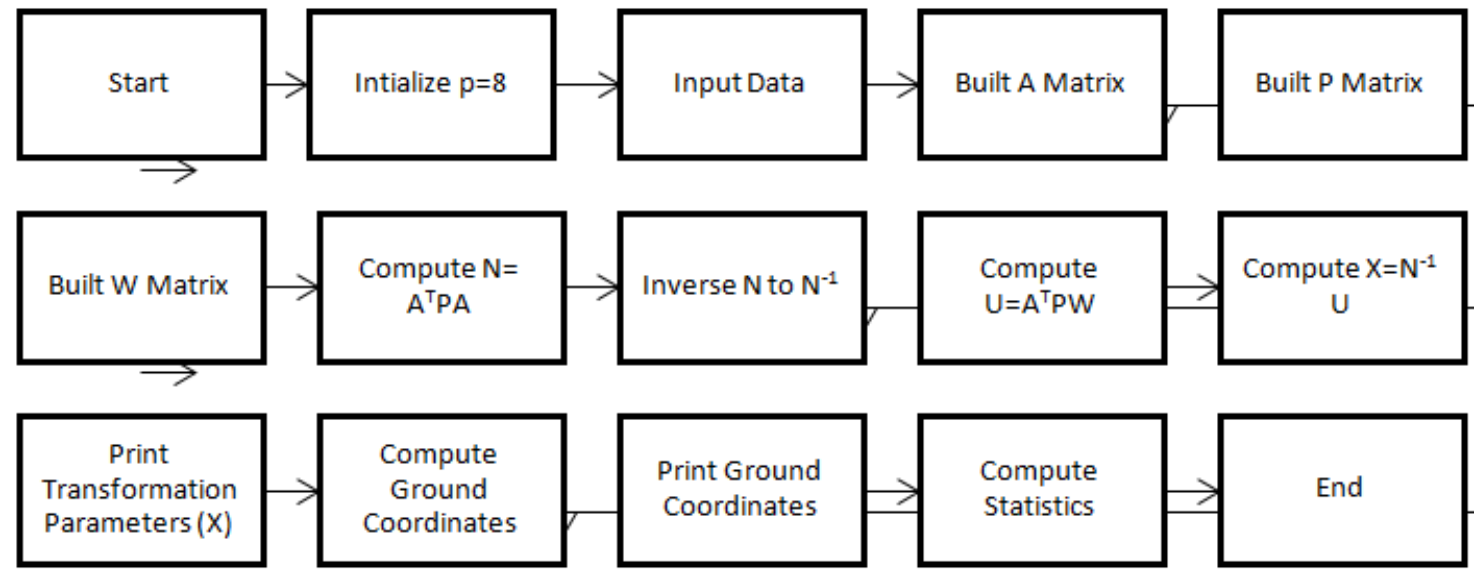

Fig. 2: Flow-Chart of DLT Program (TRANSFORM).

The steps of the TRANSFORM algorithm are:

1. Start the program.

2. $\mathrm{P}=8$ (No. of Transformation Parameters).

3. Insert input files.

4. Built A Matrix using left hand side of the equation (5).

5. Built P Matrix equal weight.

6. Built $\mathrm{w}$ Matrix using right hand side of the equation (5).

7. Compute $\mathrm{N}=\mathrm{A}^{\mathrm{T}} \mathrm{PA}$

8. Inverse $\mathrm{N}$ to $\mathrm{N}^{-1}$.

9. Compute $U=A^{T} P w$.

10. Compute $X=N^{-1} U$.

11. Print Transformation Parameters (X).

12. Compute ground coordinates from equations $(6,7)$.

13. Print ground coordinates.

14. Compute statistics:

$$
\begin{aligned}
& \Delta X^{\prime}=X_{\text {TS }}^{\prime}-X^{\prime} \text { computed } \\
& \Delta Z^{\prime}=Z_{\text {TS }}^{\prime}-Z^{\prime} \text { computed } \\
& \Delta P=\sqrt{ }\left((\Delta X)^{2}+(\Delta Z)^{2}\right) \\
& \text { RMS } \left.=\sqrt{ }\left(\sum \Delta P^{2}\right) / n\right)
\end{aligned}
$$

Where:

$\mathrm{X}_{\text {TS }}^{\prime}$ : $\mathrm{X}^{\prime}$ coordinate of Total Station in $\mathrm{X}^{\prime} \mathrm{Z}^{\prime}$ system.

$\mathrm{X}^{\prime}$ computed: Computed $\mathrm{X}^{\prime}$ of the TRANSFORM program in $\mathrm{X}^{\prime} \mathrm{Z}^{\prime}$ system.

$\Delta X^{\prime}: X^{\prime}$ coordinate discrepancy.

$\Delta Z^{\prime}: Z^{\prime}$ coordinate discrepancy.

$\triangle \mathrm{P}$ : Positional discrepancy.

RMS: Root Mean Squares.
15. End of Run.

\section{C.OUTPUT DATA:}

The output data is a (*.txt) file that contain the transformation parameters, the transformed points with its details, the mean of $\Delta X^{\prime}$ and its RMS, the mean of $\Delta Z^{\prime}$ and its $\mathrm{RMS}$, the mean of $\Delta \mathrm{P}$ and its RMS.

\section{DESCRIPTION OF FIELD EXPERIMENT AND MEASUREMENTS:}

The field experiment was done on two vertical façades located in Faculty of Engineering, Ain Shams University, Cairo, Egypt. From Fig. 3a and Fig. 3b, it can be seen that, such image contains our tested façades, which the selected points are in one vertical plane (the main vertical plane of the façade). To test the accuracy, reliability and applicability of using the developed computer algorithm with one digital image in surveying and recording of artificial façades, two field experiments were made on the two façades:

- Capturing the images with different distances from the façade and different common points.

- Capturing the images with different orientation angles to the façade and different common points.

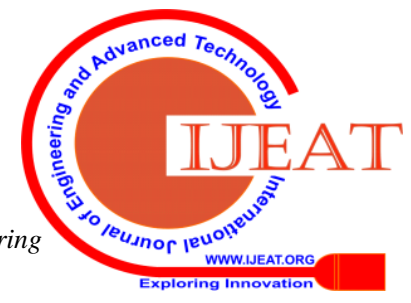




\section{Simplifying of DLT Equations for a Single Digital Image and its Application in Architectural Façades Documentation}

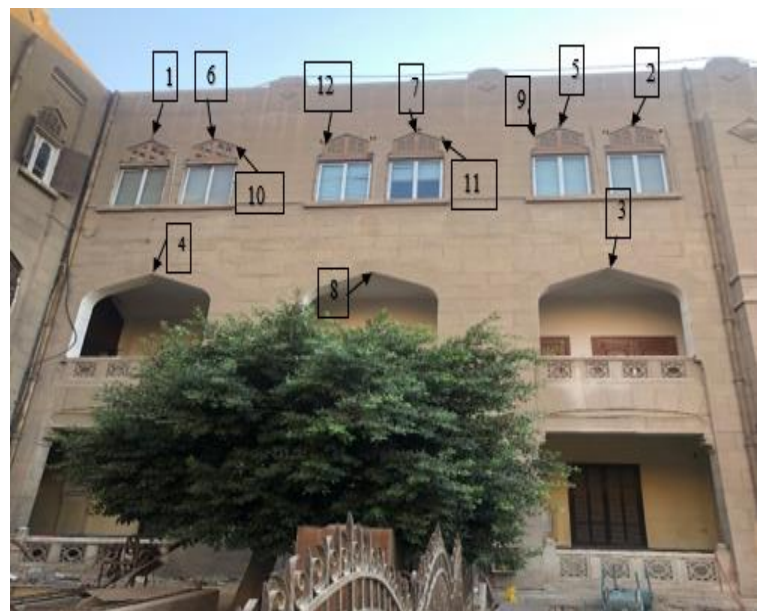

Fig. 3a: The image of the Left façade.

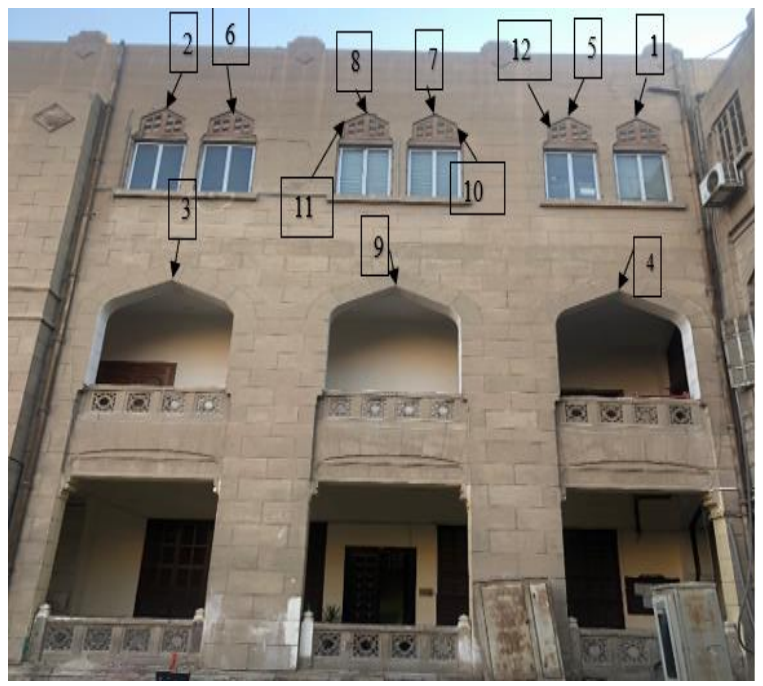

Fig. 3b: The image of the Right façade.

The used data captured device is a high precision and easy to use i-phone 8 camera with 12 mega pixels to record the two façades. For each façade, the image coordinates of 12 points were measured. Also, the three-dimensional coordinates of the same 12 points are measured using total station (Trimble M3 DR Series) with a measuring precision of 2" in angles and $2 \mathrm{~mm}+2 \mathrm{ppm}$ in distances. Then, a coordinate transformation is done from the three-dimensional coordinate system (XYZ) to each façade coordinates system ( $\mathrm{XZ}^{\prime}$ '). Many tables are produced for each image case of the two façades. So the total number of points for the two façades are 24. Table- I shows the image coordinates $(x, y)$ and the ground Total Station transformed coordinates ( $\left.\mathrm{X}^{\prime}, 0, \mathrm{Z}^{\prime}\right)$ of the measured points of the left façade as an example for one case study:

Table- I: Image coordinates and Transformed ground coordinates of the measured points in a tested façade.

\begin{tabular}{|c|c|c|c|c|}
\hline \multirow{2}{*}{ Point No. } & \multicolumn{2}{|c|}{ Image Coordinates } & \multicolumn{2}{c|}{ Ground Coordinates } \\
\cline { 2 - 5 } & $\mathrm{x}$ (pixel) & $\mathrm{y}$ (pixel) & $\mathrm{X}^{\prime}(\mathrm{m})$ & $\mathrm{Z}^{\prime}(\mathrm{m})$ \\
\hline 1 & 556 & -817 & -2.757 & 12.885 \\
\hline 2 & 2451 & -718 & 8.000 & 12.884 \\
\hline 3 & 2357 & -1600 & 7.221 & 7.561 \\
\hline
\end{tabular}

\begin{tabular}{|c|c|c|c|c|}
\hline 4 & 563 & -1637 & -1.980 & 7.576 \\
\hline 5 & 2162 & -735 & 6.457 & 12.876 \\
\hline 6 & 813 & -804 & -1.210 & 12.880 \\
\hline 7 & 1603 & -761 & 3.370 & 12.887 \\
\hline 8 & 1429 & -1625 & 2.601 & 7.556 \\
\hline 9 & 2070 & -790 & 5.942 & 12.521 \\
\hline 10 & 892 & -849 & -0.699 & 12.530 \\
\hline 11 & 1695 & -807 & 3.889 & 12.537 \\
\hline 12 & 1238 & -830 & 1.310 & 12.539 \\
\hline
\end{tabular}

\section{RESULTS:}

The computer algorithm designed, in the current research paper, by the authors is run on the collected data. In the first step of such software, the eight transformation parameters in equation (5) are obtained by parametric least squares adjustment method, using common points. After this, the coordinates of the rest points are computed in the façade coordinates system, as mentioned before, using equations (6) and (7). Then, for testing the accuracy of the single digital image in façade survey and record, the discrepancies between the measured coordinates of the remaining points and the computed coordinates are calculated for each façade. The points of each façade are divided into two groups. The first group (7 points) is used to calculate the transformation parameters of the modified DLT (8 parameters) starting from 4 common points. The second group (5 points) is used to evaluate the algorithm and the modified DLT.

\section{A.THE FIRST EXPERIMENT.}

In the first experiment, different images with different distances (resolutions) are captured for the two façades, and different number of common points in the two façades are used to test the effect of resolution and number of common points on the obtained accuracy. In this context, RMS is calculated for each case to assess the obtained accuracy. Table- II, Fig. 4 and Fig. 5 show the results of the first experiment (capturing the images with different distances (image resolutions) from the façade and different common points) for the first façade (left façade). Also, Table- III, Fig. 6 and Fig. 7 show the results of the first experiment (capturing the images with different distances from the façade and different common points) for the second façade (right façade). 
Table- II: RMS for image resolutions and data redundancy for the left façade.

\begin{tabular}{|c|c|c|c|c|}
\hline Image resolution (mm) & $\begin{array}{c}\text { 4pts. RMS (mm) } \\
\text { 0\% Redundancy }\end{array}$ & $\begin{array}{c}\text { 5pts. RMS (mm) } \\
\text { 25\% Redundancy }\end{array}$ & $\begin{array}{c}\text { 6pts. RMS (mm) } \\
\text { 50\% Redundancy }\end{array}$ & $\begin{array}{c}\text { 7pts. RMS (mm) } \\
\text { 75\% Redundancy }\end{array}$ \\
\hline 5.7 & $\mathbf{9}$ & $\mathbf{9}$ & $\mathbf{9}$ & $\mathbf{9}$ \\
\hline 6.9 & $\mathbf{8}$ & $\mathbf{8}$ & $\mathbf{8}$ & 7 \\
\hline 8.2 & 13 & $\mathbf{9}$ & $\mathbf{8}$ & $\mathbf{8}$ \\
\hline 9.6 & 15 & 13 & 11 & 10 \\
\hline
\end{tabular}

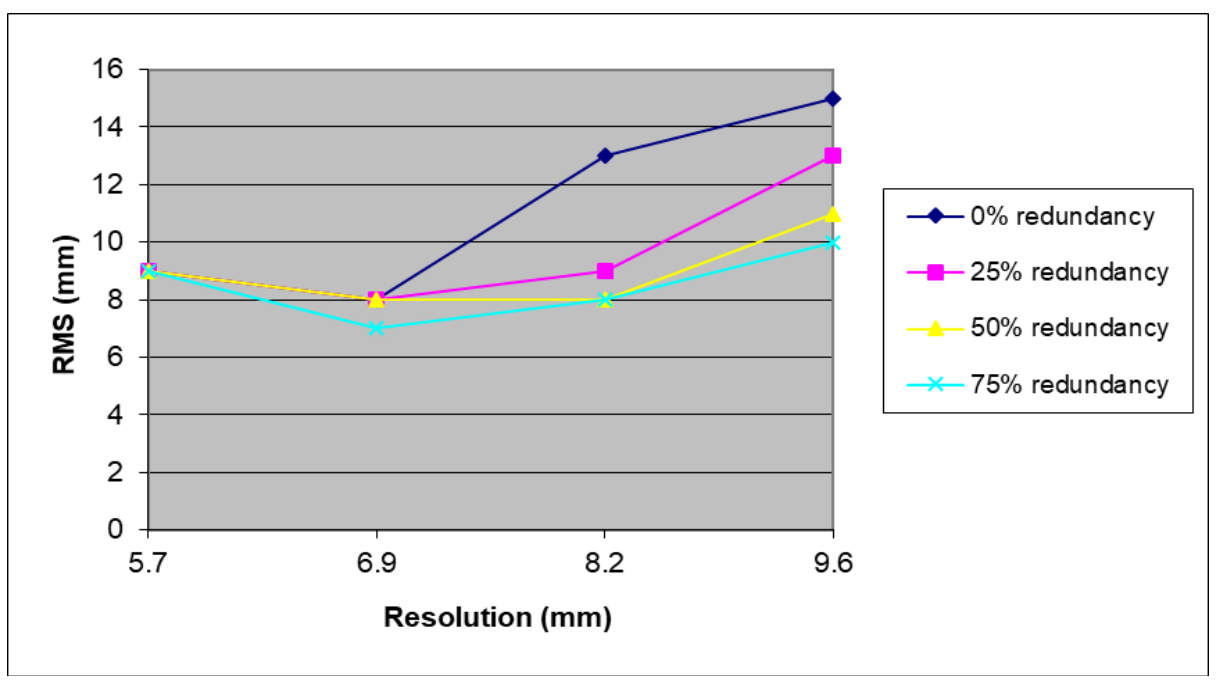

Fig. 4: RMS of image resolution for the left façade.

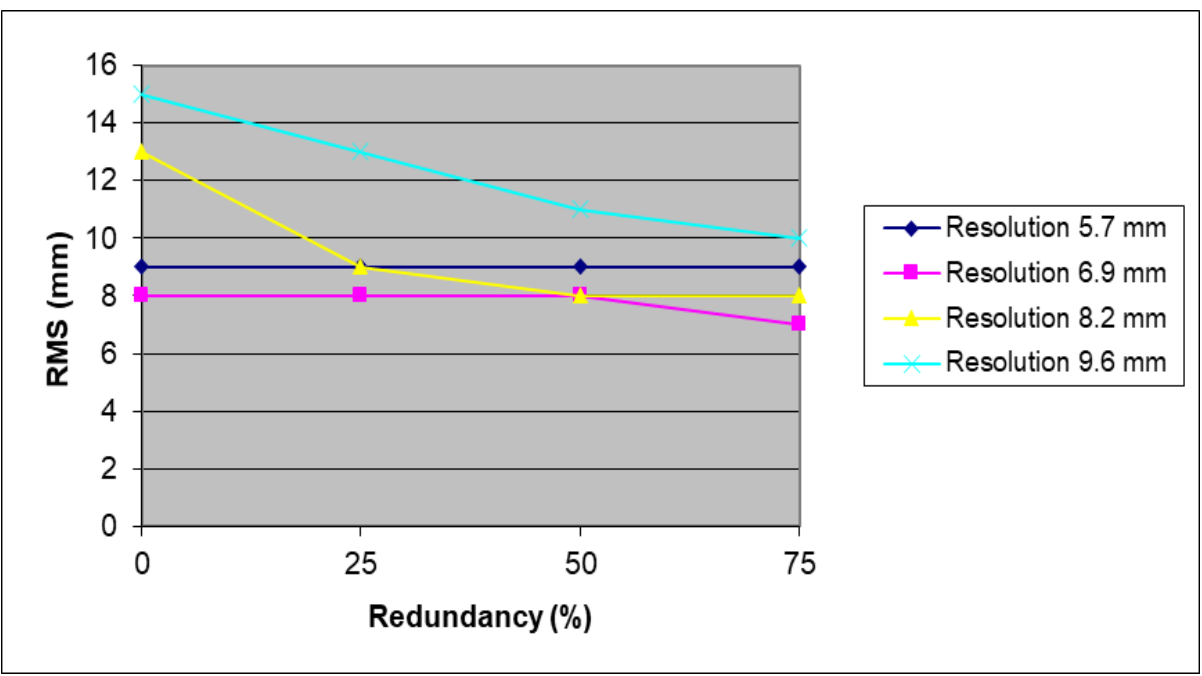

Fig. 5: RMS of data redundancy for the left façade.

Table- III: RMS of image resolutions and data redundancy for the right façade.

\begin{tabular}{|c|c|c|c|c|}
\hline Image resolution (mm) & $\begin{array}{c}\text { 4pts. RMS (mm) } \\
\text { 0\% Redundancy }\end{array}$ & $\begin{array}{c}\text { 5pts. RMS (mm) } \\
\text { 25\% Redundancy }\end{array}$ & $\begin{array}{c}\text { 6pts. RMS (mm) } \\
\text { 50\%Redundancy }\end{array}$ & $\begin{array}{c}\text { 7pts. RMS (mm) } \\
\text { 75\% Redundancy }\end{array}$ \\
\hline 5.6 & 7 & 7 & 7 & 7 \\
\hline 6.8 & 9 & 10 & 9 & 8 \\
\hline 8.4 & 16 & 12 & 10 & 9 \\
\hline 9.7 & 19 & 14 & 13 & 10 \\
\hline
\end{tabular}




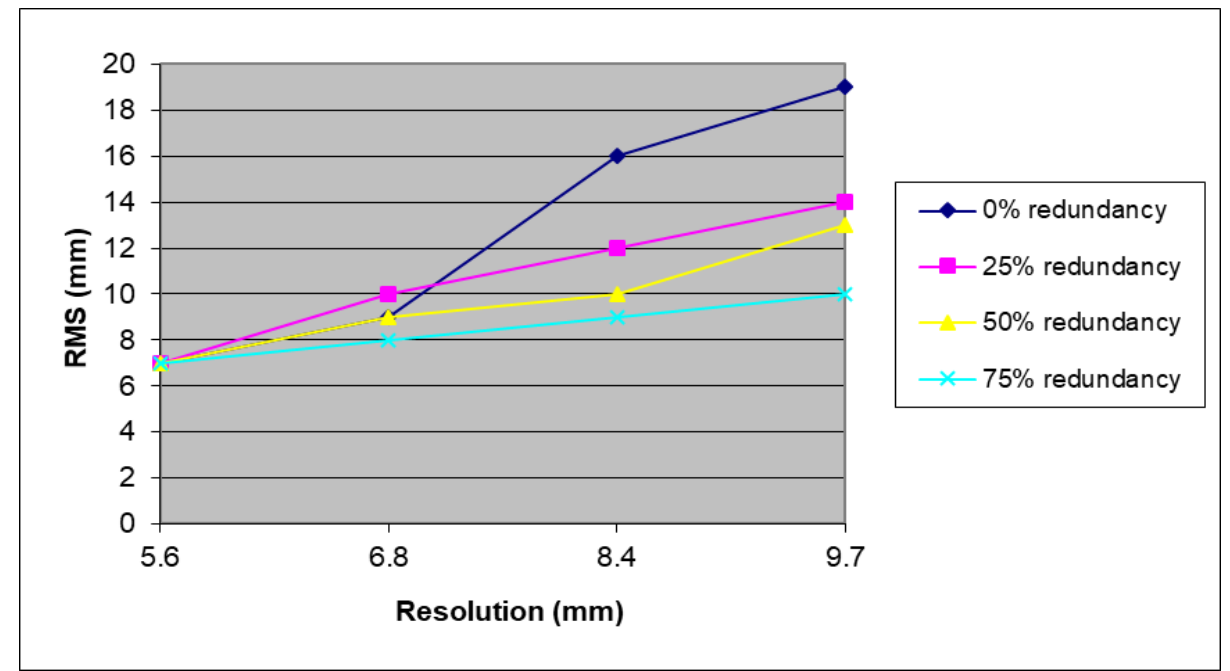

Fig. 6: RMS of image resolutions for the right façade.

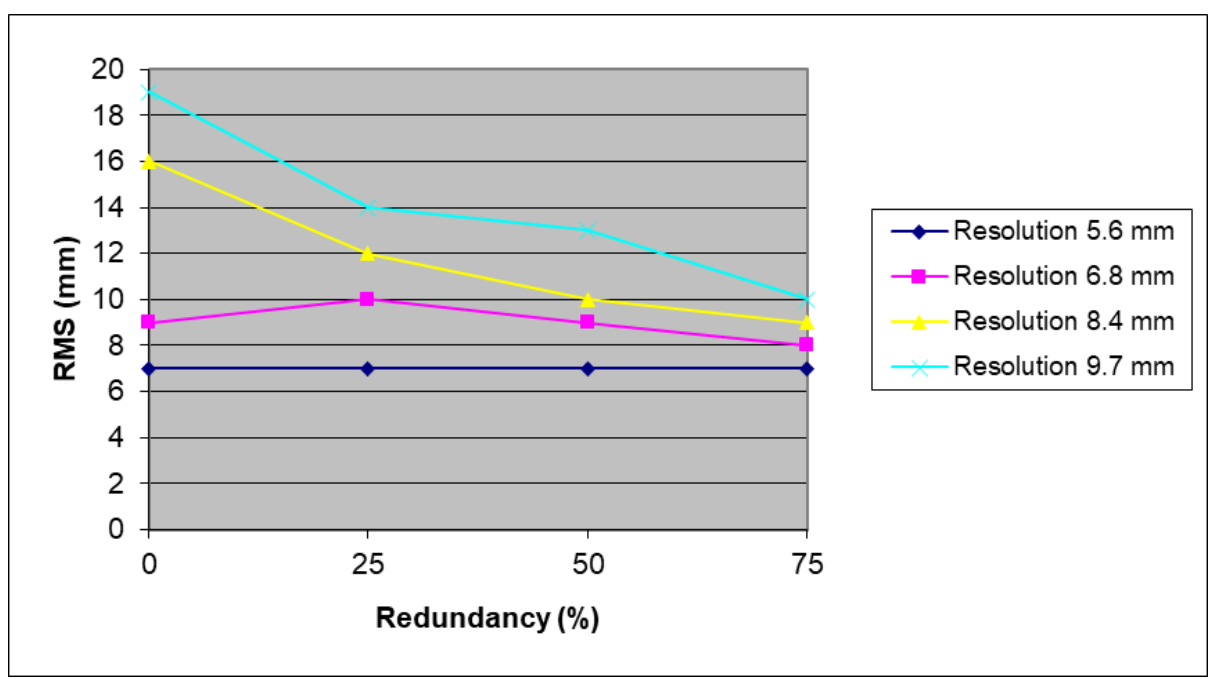

Fig. 7: RMS of data redundancy for the right façade.

\section{B.THE SECOND EXPERIMENT}

In the second experiment, different image orientations with the same resolution of $7.2 \mathrm{~mm}$ are captured for the two façades to test the effect of image orientation on the obtained accuracy. In this context, RMS is calculated for each case to assess the obtained accuracy. Table- IV and Fig. 8 show the results of the second experiment (Capturing the images with different orientation angles to the façade. So, the image plane makes an angle with the the façade's $\mathrm{Y}$-axis of $90^{\circ}, 80^{\circ}$, and $70^{\circ}$ ) for the left façade. Also, Table- $\mathrm{V}$ and Fig. 9 show the results of the second experiment for the right façade.

Table- IV: RMS of image orientations and data redundancy for the left façade.

\begin{tabular}{|c|c|c|c|c|}
\hline $\begin{array}{c}\text { Image } \\
\text { orientation }\end{array}$ & $\begin{array}{c}\text { 4pts. RMS (mm) } \\
\text { 0\% Redundancy }\end{array}$ & $\begin{array}{c}\text { 5pts. RMS (mm) } \\
\text { 25\% Redundancy }\end{array}$ & $\begin{array}{c}\text { 6pts. RMS (mm) } \\
\text { 50\% Redundancy }\end{array}$ & $\begin{array}{c}\text { 7pts. RMS (mm) } \\
75 \% \text { Redundancy }\end{array}$ \\
\hline $90^{\circ}$ & 13 & 10 & 10 & 9 \\
\hline $80^{\circ}$ & 8 & 7 & 7 & 7 \\
\hline $70^{\circ}$ & 9 & 8 & 7 & 7 \\
\hline
\end{tabular}




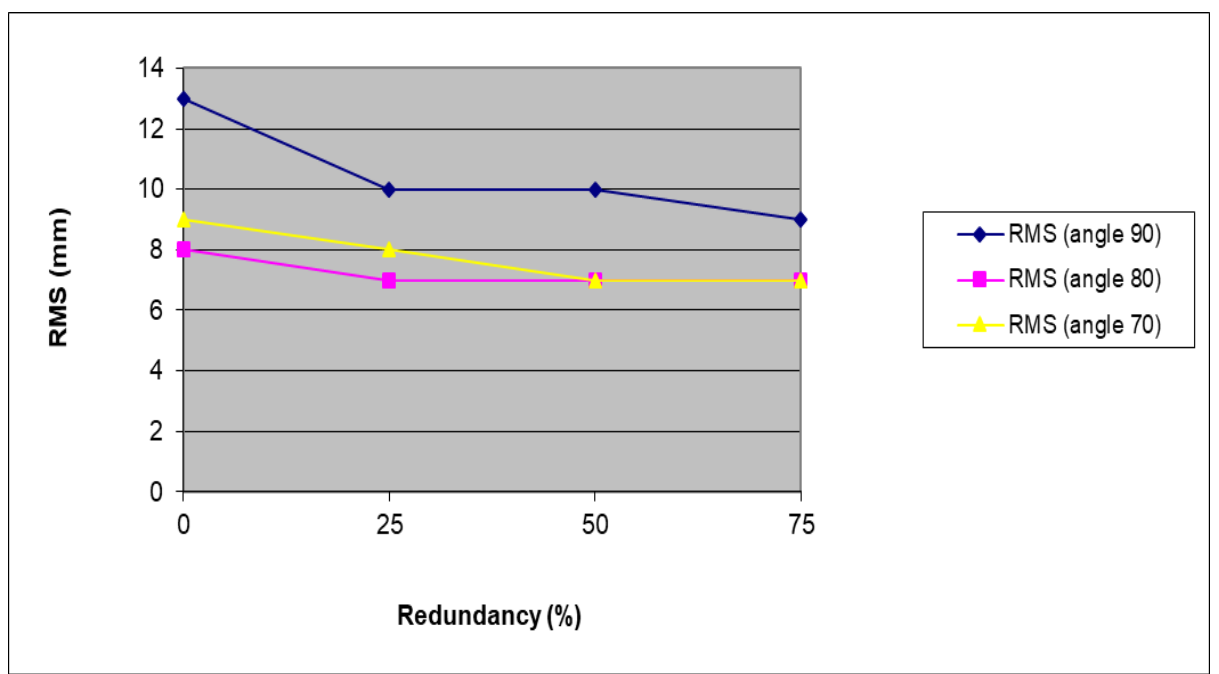

Fig. 8: RMS of data redundancy for the left façade with different orientations.

Table- V: RMS of image orientations and data redundancy for the right façade.

\begin{tabular}{|c|c|c|c|c|}
\hline Image orientation & $\begin{array}{c}\text { 4pts. RMS (mm) } \\
\text { 0\% Redundancy }\end{array}$ & $\begin{array}{c}\text { 5pts. RMS (mm) } \\
\text { 25\% Redundancy }\end{array}$ & $\begin{array}{c}\text { 6pts. RMS (mm) } \\
\text { 50\% Redundancy }\end{array}$ & $\begin{array}{c}\text { 7pts. RMS (mm) } \\
\text { 75\% Redundancy }\end{array}$ \\
\hline $\mathbf{9 0}^{\circ}$ & $\mathbf{1 9}$ & $\mathbf{1 6}$ & $\mathbf{1 1}$ & $\mathbf{1 1}$ \\
\hline $\mathbf{8 0}^{\circ}$ & $\mathbf{8}$ & $\mathbf{7}$ & 7 & $\mathbf{6}$ \\
\hline $\mathbf{7 0}^{\circ}$ & $\mathbf{1 4}$ & $\mathbf{1 2}$ & $\mathbf{1 2}$ & $\mathbf{1 0}$ \\
\hline
\end{tabular}

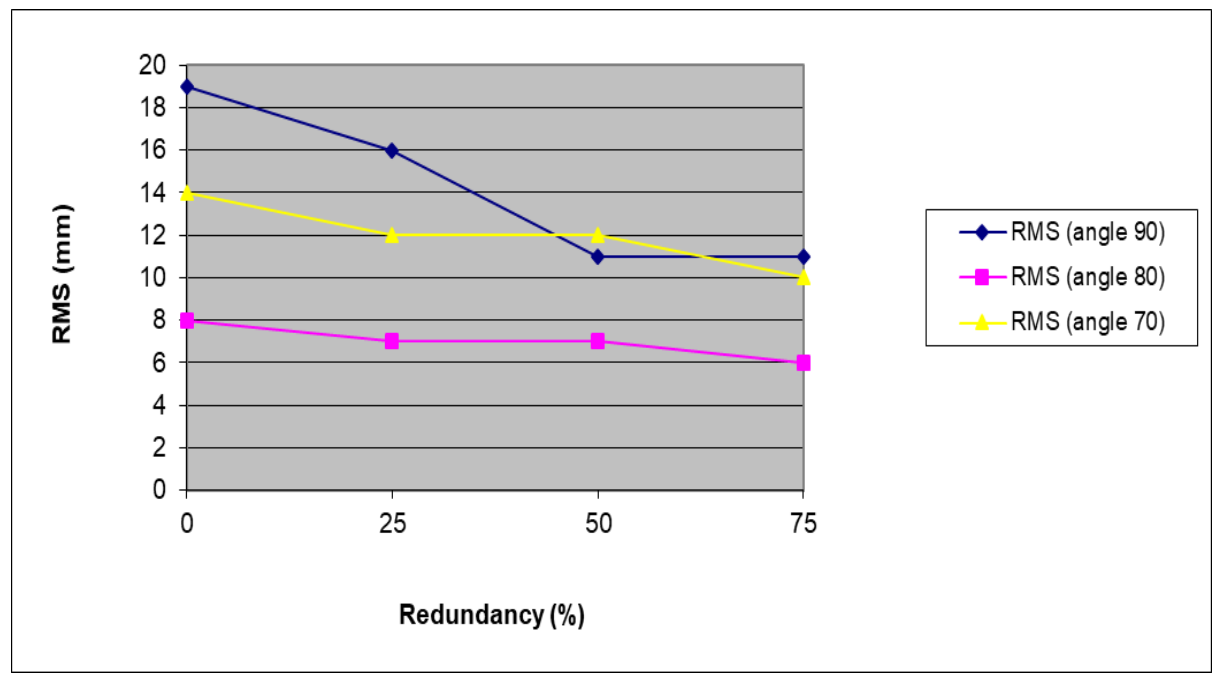

Fig. 9: RMS of data redundancy for the right façade with different orientations.

\section{ANALYSIS OF OBTAINED RESULTS:}

For the first experiment, examination of image resolution effect on the obtained positional accuracy, the investigation of Table- II and Table- III as well as Fig. 4, Fig. 5, Fig. 6, and Fig. 7 indicates that:

- The accuracy does not improve with decreasing the image resolution because the accuracy affected by the accuracy of Total Station and paper prism Points. This means that, the decreasing of the image resolution must be associated with increasing the accuracy of control points to increase accuracy.

- The accuracy improved with increasing the redundancy till 75\% redundancy.

- The accuracy ranges from $7 \mathrm{~mm}$ to $19 \mathrm{~mm}$ with image resolution equal or lower than $9.7 \mathrm{~mm}$.

For the second experiment, examination of image orientation angle effect on the obtained positional accuracy, the investigation of Table- IV and Table- $\mathrm{V}$ as well as Fig. 8 and Fig. 9 indicates that:

- The effect of orientation angle of the image on the obtained accuracy is very small because the mathematical model treats the orientation of the image.

- The accuracy improved with increasing the redundancy till 75\% redundancy (system saturated).

\section{CONCLUSION.}

One of the main problems, facing the façade documentation, is the surveying of the position of points on the façade for map production. This problem has been solved, in an automatic manner, through the development of the computer algorithms working using least squares adjustment method as appearing in the present study.

Published By:

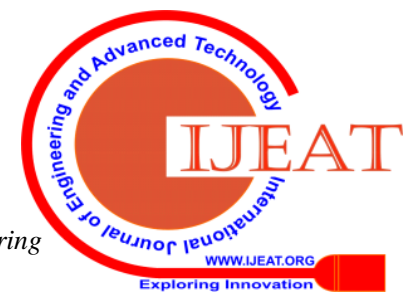




\section{Simplifying of DLT Equations for a Single Digital Image and Its Application in Architectural Façades Documentation}

The obtained results (of two different façades) indicated that, the developed program named TRANSFORM, is capable of solving such problem in a simple way.

On the other hand, it can be concluded here that, the decreasing of the image resolution must be associated with increasing the accuracy of control points to increase accuracy. Also, the increasing of the common points to calculate the transformation parameters increase the accuracy till $75 \%$ redundancy. The obtained accuracy for façade documentation using single image is from $7 \mathrm{~mm}$ to $19 \mathrm{~mm}$ with image resolution equal or lower than $9.7 \mathrm{~mm}$.

The developed software of the present paper is recommended to be efficiently used for automatic computation of façade points from single image, with minimum field work.

\section{REFERENCES}

1. Andrea, L.; P. Piumatti; and F. Rinaudo, 2001, "Digital Photogrammetry: A Standarad Approach to Culture Heritage Survey", CIPA 2001 international symposium, 18-21 Sept., Potsdam, Germany.

2. Burchardt, C.B. and K. Voss, 2004, "Façade Reconstruction of Destroyed Building Using Historical Photographs, ISPRS Congress, 12-23 July 2004 Istanbul, Turkey.

3. Cantoni, R.; G. Vassena and C. Lanzi, 2003, "Architectural Representation Through Digital Photogrammetry of The South Façade of (La Loggia) Palace in Brescia (Italy)", International workshop on Vision Technologies for Digital Architectural and Archaeological Archieves, 1-3 July 2003, Portonona - Ancoma, Italy.

4. Ligua, A.; P. Piumatti; and F. Rinaudo, 2003, "Digital Photogrammetry: A Standard Approach to Cultural Heritage Survey", International workshop on Vision Technologies for Digital Architectural and Archaeological Archieves, 1-3 July 2003, Portonona - Ancoma, Italy.

5. Nathalie Van Roy, Koen Van Balen, Els Verstrynge and Silvia Naldini 2015-21(4-6): 137-148, "The Stratified Significance of a Historic Façade as a Basis for a more Durable Conservation Approach",KU Leuven, Heverlee - Belgium.

6. Pomaska, G., 1998, “Automated Processing of Digital Image Data In Architectural Surveying, ISPRS Symposium, Real-Time Imaging and dynamic Analysis, 2-5 June, Hakodate, Japan.

7. Likun Liu \& Zhenfeng Shao (2015) "Calibration of digital camera integration accuracy for low-cost oblique aerial photogrammetry", Geo-spatial Information Science, 18:2-3, 90-96.

8. Abdel-Gawad, A.K., 2000, "Development of Special software Package for automatic Interpretation of Space Imagery and Its Applications for Some Environmental Studies", Ph.D Thesis, Faculty of Engineering, Ain Shams University, Cairo, Egypt.

9. Abed El-Aziz, Y.A. and Karara, H.M., 1978, "Direct Linear Transformation from Comparator Coordinates into Object Space Coordinates in Close-Range Photogrammetry", Proceedings of the ASP/UI Symposium on Close-Range Photogrammetry, pp. 420-475.

10. Shaker, I.F., 1988,"Beitrage Zur Anwendung der Digitalen Bildverarbeitung in der Nahphotogrammetrie", Ph.D thesis, Technical University, Berlin, Germany.

11. Samuel Kotz; N. Balakrishnan; Campbell Read Brani Vidakovic, 2006, "Gauss-Helmert Model" Encyclopedia of statistical sciences, Wiley. doi:10.1002/0471667196.ess0854.

\section{AUTHORS PROFILE}

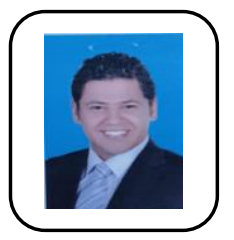

Mohamed A. M. Abbas, Researcher at Public Works Department, Faculty of Engineering, Ain Shams University, Egypt. Surveying Engineer at Survey Unit, Faculty of Engineering, Ain Shams University, Egypt. Email: mohamed.abbas9215@gmail.com

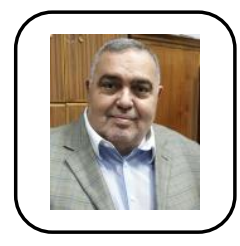

Ibrahim F. Shaker, Professor of Surveying and Photogrammetry Public Works Department, Faculty of Engineering, Ain Shams University, Egypt. Ex-Vice Dean of Faculty of Engineering, Ain Shams University, Egypt. Research Activity includes: Photogrammetry, GIS, Engineering Survey, Digital Image Processing.

Email: ibrahim.shaker@eng.asu.edu.eg

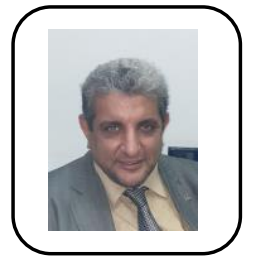

Ahmed K. Abdel-Gawad, Professor of Civil Engineering, Civil Engineering Department, National Research Centre, Egypt. Head of Civil Engineering Department, National Research Centre. Head of Civil and Architecture Engineering Consulting Unit of National Research Centre. Research Activity includes: Engineering Surveying, GIS, Photogrammetry.

Email: ahmed khedre@yahoo.com

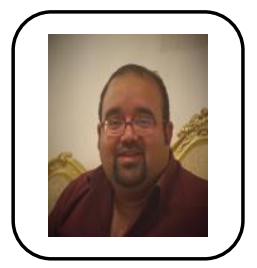

Alaa Al Din I. Awad, Assistant Professor of Ssurveying, Public Works Department, Faculty of Engineering, Ain Shams University, Egypt. Research Activity includes: Engineering Surveying, Geodetic and Satellite Surveying, Photogrammetry. Email: alaa.ibrahim@eng.asu.edu.eg 